\title{
O universo fantástico de Murilo Rubião
}

\author{
Suzana Yolanda L. Machado Cánovas
}

Resumo: This article examines the particular, recurrent and circular movement in the fantastic world of Murilo Rubião. This movement has been identified by Davi Arrigucci in Rubião's work in various aspects: in his infinite writing process, in the occurrence of obsessive topics of multiplication and metamorphosis, in the use of biblical epigraphies and in the dissolution of the historical time.

Palavras-chave: narrativa fantástica; autores mineiros; contos brasileiros

Murilo Eugênio Rubião nasceu em Silvestre Ferraz, hoje Carmo de Minas, no dia $1^{\circ}$ de junho de 1916 e morreu em Belo Horizonte, onde viveu a maior parte de sua vida, em 16 de setembro de 1991. Com exceção dos quatro anos em que morou na Espanha, como Adido Cultural da Embaixada do Brasil, nunca abandonou o solo mineiro.

-O escritor começou a escrever no final da década de 30, tendo publicado seu primeiro conto, "Elvira e outros mistérios", na revista Mensagem, em 1940. Mas o autor, segundo depoimento de Hélio Pellegrino, começou sua vida literária como poeta :

Começou a escrever aos 16 anos, sob o signo das musas. Seus primeiros dois livros (de poesia) foram dedicados a uma namorada. Acabou perdendo a namorada, como sói acontecer nessa idade, e rasgou os livros (sem que dessa ação guarde o menor remorso). ${ }^{1}$

Suzana Yolanda L. Machado Cánovas é professora de Introdução aos Estudos Literários e Literatura Comparada na UFG. Doutora em Letras pela UFRGS.

'PELLEGRINO, Hélio. Espelho dos escritores. Suplemento Literário do Minas Gerais, Belo Horizonte, v.22, n. 1.061, p. 5, 14 fev. 1987. (Especial 2). Texto publicado primeiramente na Revista da Semana, edição de 23 de janeiro de 1954. 
CÁNOVAS, Suzana Yolanda L. M.

Murilo Rubião escreveu também crônicas e contos, que foram publicados em jornais e revistas da década de 40 . Assim como os poemas, eles apresentam o traço juvenil do autor, com muitas reticências e pontos de exclamação, mas que já fornecem elementos para a compreensão de sua obra. ${ }^{2}$

O autor estreou com o livro $O$ ex-mágico, em 1947, mas permaneceu desconhecido do grande público até o lançamento de Opirotécnico Zacarias, em 1974. É com esse livro que o escritor é consagrado e lhe é reconhecido um lugar na moderna literatura latino-americana. É digno de nota o fato de $O$ ex-mágico ser lançado antes da explosão da literatura latino-americana, antecedendo a publicação de $O$ bestiário, de Julio Cortazar, em 1951. Mas é somente quando a literatura latino-americana chama a atenção dos leitores brasileiros que a obra do autor mineiro, que antecede suas experiências estéticas, torna-se conhecida. É isso que leva Edilberto Coutinho a afirmar que foi através do contato com os hispânicos que os brasileiros descobriram Murilo Rubião. ${ }^{3}$

O impacto causado pelo livro de estréia mostra a profunda ruptura que sua narrativa representa em razão dos traços de um moderno fantástico alegórico sem precedentes em nossa literatura. Assim, Murilo Rubião é pioneiro no tratamento do tema na literatura brasileira, que hoje conta com expoentes como Moacyr Scliar. O próprio autor declara em entrevista a origem de sua preferência pelo fantástico:

Minha opção pelo fantástico foi herança da infância, das intermináveis leituras de contos de fadas, do "Dom Quixote", da "História Sagrada" e das "Mil e uma noites". Ainda: porque sou um sujeito que acredita no que está além da rotina.Nunca me espanto com o sobrenatural, com o mágico. E isso tudo aliado a uma sedução profunda pelo sonho, pela atmosfera onírica das coisas. Quem não acredita no mistério não faz literatura fantástica. ${ }^{4}$

Tendo sido encontrada em sua obra uma semelhança com Kafka, o escritor nunca admitiu que tivesse sofrido influência do autor tcheco, declarando que na década de 40 ninguém no Brasil, com exceção de Mário de Andrade, conhecia Kafka e que só teve contato com sua obra quando grande parte dos contos de $O$ ex-mágico tinha sido escrita. É a Machado de Assis que ele atribui a grande influência que recebeu, tributando a ele a sua op-

${ }^{2} \mathrm{Cf}$. Acervo de Escritores Mineiros -FALE/BU/UFMG.

${ }^{3}$ COUTINHO, Edilberto. No habló, não estava com nada. O Globo, Rio de janeiro, 7 abr. 1977. ${ }^{4}$ MURILO Rubião. Busca desesperada da clareza. In: _. Seleção de textos, notas, estudos biográfico, histórico e crítico e exercícios por Jorge Schwartz. São Paulo: Abril Educação, 1982. p.3 (literatura comentada) 
ção pelo gênero em que produziu suas narrativas: "Eu cheguei ao fantástico exatamente por ter começado pelo Machado. Sem ele eu não chegaria ao fantástico nunca." ${ }^{5}$

Quando empreendemos um estudo da produção literária do escritor mineiro, deparamo-nos com um paradoxo detectado primeiramente em sua própria pessoa. Há um Murilo Rubião funcionário público, que exerce cargos de destaque, metódico e centrado na realidade empírica, tal como ela se apresenta ao olho racional que não perscruta mistérios. Mas existe também seu duplo, o artista. A personagem de "O ex-mágico da Taberna Minhota" ${ }^{6}$ nasce já adulto através do espelho e é um criador de prodígios. O escritor surge com uma obra literária que, como a superfície duplicadora na Taberna Minhota, mimetiza um universo de ilusões. Tal como o mágico, que não se surpreende com o fato de arrancar do bolso o dono do restaurante, o autor também não se espanta com o insólito.

No interior de sua obra literária, ele repete o mesmo paradoxo do homem, pois se desdobra, de um lado, na preocupação com o elemento apolíneo de ordem e racionalidade e, de outro, com o irromper dionisíaco da transgressão representada pelo fantástico. O primeiro aspecto evidencia-se na profunda preocupação com a linguagem, que o leva a uma constante retomada de suas narrativas que, de livro para livro, aparecem reescritas. Detectando esses dois elementos, Rui Mourão, que compara o autor com Machado de Assis, comenta:

Um aspecto geral comum aos dois escritores é o contraste entre uma linguagem policiada, disciplinada, despojada - rigorosamente enquadrada na lógica gramatical mais cristalina - e uma invenção do mundo fantasista, alucinada e ingovernável. No plano da frase, o escritor está sempre à cata do termo próprio, da precisão substantiva, se excede no uso de elementos de ligação, de desdobramentos explicativos; no plano das unidades superiores à frase, está sempre à procura do vago, da duplicidade significante, se desmanda no uso de elementos que visam à desconexão, à produção do desconforto e das surpresas chocantes. Parece que o objetivo é o de deixar o leitor pisando ao mesmo tempo no plano do lógico e do ilógico, do verossimilhante e do desconhecido - numa continuada denúncia do que na realidade existe de incongruente e de compósito.$^{7}$

${ }^{5}$ Id., ibid., p. 3 .

${ }^{6}$ As notas sobre as narrativas, que estão incluídas em Contos reunidos (São Paulo: Ática, 1998), constarão apenas do título e da página.

${ }^{7}$ MOURÃO, Rui. Um discípulo de Machado. Suplemento Literário do Minas Gerais. Belo Horizonte, 14 jul. 1974. 
CÁNOVAS, Suzana Yolanda L. M.

Entretanto, se percebemos, com Mourão, uma dicotomia entre a clareza, a rigidez do léxico e da sintaxe e a ilogicidade do mundo representado, o escritor mineiro vê na permanente busca de clareza e na precisão da linguagem de suas narrativas não um paradoxo capaz de confundir o leitor, mas um aspecto utilitário e funcional que concerne ao fantástico:

\begin{abstract}
uma das coisas que eu queria atingir era exatamente a clareza porque, sabendo que os meus contos eram difíceis, não queria perturbar o leitor com a linguagem [...] Assim, procuro fazer com que o leitor atente apenas para o simbolismo da minha história. As palavras devem ser as mais transparentes possíveis para que o leitor não sinta a sua a presença. Elas devem ser instrumentos da minha história, pois o fantástico exige isto. Esta clareza de linguagem é muito pertinente ao fantástico $[. . .]^{8}$
\end{abstract}

Quer isso se considere um paradoxo do mundo muriliano ou se aceitem as razões dadas pelo próprio ficcionista, o fato é que, da forma de composição lúcida, racional e elaborada, emana um universo insólito e perturbador. Todavia, esse mundo é instalado no território da cotidianidade, o que nos faz pensar no ensaio de Freud, Das unheimliche, traduzido em português como "O estranho", termo que, segundo o psicanalista, "é aquela categoria do assustador que remete ao que é conhecido, de velho, e há mui-

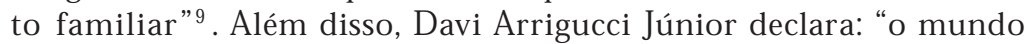
muriliano é produto da intenção de um autor que busca a construção harmoniosa dos elementos insólitos no contexto da realidade habitual, mediante a paralisação da surpresa" ${ }^{10}$.

Mas, conforme o crítico, o universo muriliano é e não é o do leitor, pois tem afinidade com o mundo dos sonhos, devido à quebra da verossimilhança, no que respeita às leis da causalidade, do tempo e do espaço ou da identidade das personagens. De fato, a aproximação da narrativa de Murilo Rubião com o contexto onírico é confirmada por ele próprio, quando diz possuir "uma sedução profunda pelo sonho, pela atmosfera onírica das coisas". ${ }^{11}$

${ }^{8}$ RUBIÃO, Murilo. Auto-retrato. In: NUNES, Sandra Regina Chaves. Murilo Rubião: escrita e reescrita. 1996. Dissertação (Mestrado em Comunicação e Semiótica) - Pontifícia Universidade Católica, São Paulo, 1996. p. 42.

${ }^{9} \mathrm{FREUD}$, Sigmund. O estranho. In: _. Edição standard das obras psicológicas completas de Sigmund Freud.Rio de Janeiro: Imago, 1986. v.17. p. 271-314.

${ }^{10}$ ARRIGUCCI JÚNIOR, Davi. Minas, assombros e anedotas. (Os contos fantásticos de Murilo Rubião). In: __. Enigma e comentário: ensaios sobre literatura e experiência. São Paulo: Companhia das Letras, 1987. p. 141-165.

${ }^{11}$ MURILO Rubião. Busca desesperada da clareza, p.3. 
Às vezes trata-se de um devaneio, como em "Ofélia, meu cachimbo e o mar", narrativa em que o protagonista, aconchegado na noite calma e benfazeja, numa situação propícia ao devaneio, sentado após o jantar na varanda da casa, fumando cachimbo, conta a sua cachorra Ofélia histórias sobre a sua família de marinheiros.

Há casos em que o onírico é confirmado pelo próprio autor, que declara que o conto "Epidólia", no qual a mulher desaparece dos braços do namorado num banco do parque, nasceu de um sonho. ${ }^{12}$ Nesse conto, no interior do próprio universo ficcional, está sugerida a realidade onírica, já que o protagonista está de pijama em plena via pública. Em alguns momentos, o sonho adquire a forma de um pesadelo, como no caso de "Petúnia" em que escorre a maquilagem do retrato da mãe do protagonista, tornando possíveis as mais aterrorizantes cenas surrealistas, como as rosas negras que brotam do ventre da figura feminina e invadem a casa, e os estranhos rituais noturnos de meninas assassinadas que, sendo gente e flor a um só tempo, são desenterradas para dançar. Também constituem exemplos significativos, mas que não se esgotam aí," A casa do girassol vermelho" e "O convidado". No primeiro, como num sonho remoto, há uma atmosfera estranha de manhã primordial em que seis personagens vão delinqüir contra um Grande Pai. No segundo, numa antevisão da morte, há um clima soturno e um percorrer de labirintos para os quais a personagem vai sendo conduzida, num intrincado caminho sem volta, por uma inquietante mulher vestida de negro. Constatada a afinidade do discurso literário com o onírico, Arrigucci Júnior compara o leitor de Murilo Rubião com o que ele chama de "sonhador cúmplice":

\begin{abstract}
o leitor, ao se identificar com o narrador ou com o personagem em que recai o foco narrativo, é levado a assumir o papel de um sonhador cúmplice. Mais precisamente, de alguém que tem a sensação de estar dentro do mundo criado, ao mesmo tempo que se vê de fora. É que o mediador para o mundo ficcional, sendo parte integrante deste, está até certo ponto distanciado, na posição de quem sonha acordado, com uma lucidez minuciosa que tende a objetivar a experiência que está vivendo e, na maioria dos casos, narrando.
\end{abstract}

\footnotetext{
12"Epidólia nasceu de um sonho. Acordei às 2 ou 3 horas da madrugada, com aquele sonho na cabeça, que acreditei ser bom. Saí rapidamente do quarto, entrei no escritório e escrevi a história. O personagem já estava com o nome de Epidólia e depois quebrei a cabeça para descobrir a origem. Nasceu com nome latino? Grego? Pesquisei e pesquisei e nada achei. Eu invento muitos nomes, mas Epidólia nunca teria me ocorrido, não fosse o sonho. Nem acho bonito, sabe? (-Ibid., p. 4)
} 
CÁNOVAS, Suzana Yolanda L. M.

Não se espantando, ele nos encaminha para a familiaridade com o insólito, fazendo do mundo de fora uma extensão do de dentro e sugerindo uma continuidade efetiva entre o fantástico e o real. ${ }^{13}$

Esse narrador (ou a personagem em quem recai o foco narrativo) é muito bem apreendido pelo crítico que, com agudeza de espírito, destaca seu papel significativo de mediador que, ao introduzir o leitor no universo ficcional, como está lúcido e não se surpreende com nada do que acontece, leva o leitor a uma familiaridade com o insólito, estabelecendo uma relação entre o real e o fantástico, o lógico e o ilógico. Assim, tendo o fantástico sido aceito como elemento do cotidiano, é possível apreender com naturalidade, por mais inusitada que seja, a realidade ficcional - que não deixa de ser também a do leitor - através de uma leitura num nível de maior profundidade.

$O$ detentor da palavra não tem a onisciência do demiurgo das narrativas de cunho mais tradicional, pois, quando não é personagem, estando, portanto, mais distanciado dos fatos narrados, seu conhecimento dos seres e das coisas está limitado ao do protagonista sobre quem recai o foco narrativo. O narrador (ou personagem) está submetido a determinada situação absurda, cujo significado desconhece, só lhe restando ir por ela de roldão, sem que ele ou alguém conheça sua origem e real significado.

O processo de escrita do autor mineiro tem chamado a atenção de quantos se debruçam sobre a sua obra. Desde seu primeiro livro, cujos contos foram trabalhados durante anos antes de sua publicação, o escritor, no que aparenta ser uma obsessiva busca de perfeição, reescreve suas histórias, que são republicadas em outros livros, com novos contos que, por sua vez, são retrabalhados para aparecerem em novas coletâneas e assim sucessivamente.

Desse processo de escrita infinita que lembra "A biblioteca de Babel" ou "O livro de areia", de Jorge Luís Borges, interrompido somente pela morte do escritor, em 1991, escaparam as crônicas e contos esparsos em jornais e revistas e as narrativas que não foram concluídas e permanecem no seu acervo. Sua obra inacabada dá-nos a certeza de que ela não poderia mesmo ter recebido um ponto final, porque, se assim fosse, fugiria à característica muriliana de edificação interminável.

O processo de (re)escrita de Murilo Rubião está tematizado no seu conto " O edifício". A construção, cuja finalidade todos desconhecem, não é acabada, sendo necessárias sucessivas gerações de operários e o engenheiro não pode cultivar a vaidade de terminá-la, pois morrerá antes que ela seja concluída. Murilo Rubião deixou seu edifício por concluir, cabendo a ou-

${ }^{13}$ ARRIGUCCI JÚNIOR, op. cit., p. 146. 
tros continuar a construção através de obras que sigam o percurso pioneiro por ele empreendido.

O mesmo tipo de movimento recorrente que se verifica no ato de escrever observa-se na temática do escritor, pois a modificação e a metamorfose constituem um tema obsessivo de suas narrativas.

Em "Petúnia”, há uma confusão de nomes que não se fixam em definitivo: Petúnia Mãe ou Petúnia Joana, que, na verdade diz chamar-se Cacilda, irrita-se com seu marido quando este denomina as filhas de Petúnia Maria, Petúnia Jandira e Petúnia Angélica, afirmando que nenhuma delas se chamava Petúnia. A mesma confusão de nomes aparece em "Os três nomes de Godofredo”, cujo protagonista é Godofredo/Robério/João de Deus e os diversos nomes se relacionam com faces sucessivas de mulheres que, parecidíssimas umas com as outras, vão sendo travestidas de detalhes como mudança da cor dos cabelos, variação na forma das sobrancelhas ou presença de algum adereço, como um anel no dedo ou um medalhão no pescoço.

Há casos em que a personagem, cujo protótipo é Teleco ("Teleco, o coelhinho”), pode metamorfosear-se em animais diversos. Isso ocorre com Alfredo, do conto homônimo, no qual se reflete, invertida, a mesma situação: a personagem se transforma em porco, nuvem, verbo e dromedário, para fugir do convívio humano, enquanto Teleco faz o mesmo para agradar as pessoas. Também há um virar e desvirar de gente em planta e até em objeto, como a bolinha negra em que se metamorfoseia Artur ("O homem do boné cinzento”). Os reinos humano, animal e vegetal aparecem intercambiados e em constantes mutações numa instabilidade que se exprime através de obsessivas metamorfoses. Há, portanto, uma atmosfera de instabilidade em que permanece dúbia a identidade dos seres. Segundo Arrigucci Júnior, trata-se "de todo um complexo temático que parece estabelecer com o processo de criação um movimento unitário e circular"14.

Tal movimento repete-se nas epígrafes bíblicas, que são outra constante na obra do escritor e que muito têm chamado a atenção dos que estudam sua produção literária, resultando daí diferentes formas de abordagem. Em se tratando de Murilo Rubião, independentemente do significado particular que possam ter com relação à narrativa a que se prendem, elas têm, na sua obra, um significado global que não pode ser descuidado.

Uma epígrafe pertence a um texto a que se prende originalmente e onde possui um determinado significado. Ao ser trazida para um novo contexto, ela vai se ligar a outro campo semântico.

Pertencendo à tradição primordial, um texto sagrado diz respeito à

${ }^{14}$ ARRIGUCCI JÚNIOR, op. cit., p. 151 
CÁNOVAS, Suzana Yolanda L. M.

atemporalidade da palavra de sempre, à potencialidade do Verbo, que, como detectamos no "Gênesis", está associado à luz e à manifestação cósmica. Gilbert Durand salienta a grande importância de um livro santo, que considera um "tutor cultural":

Desde logo, vê-se o papel que desempenha, e que deve desempenhar em uma experiência simbólica autêntica, quer dizer, enriquecedora, a provisão de hormônios simbólicos guardados numa tradição e, mais especificamente, em um livro santo. Henry Corbin demonstrou muitas vezes, [...], a importância do Livro como reservatório energético do Verbo. Isto é verdade com respeito ao Corão e mais ainda com relação à Bíblia e ao Novo Testamento. [...] O Livro é uma revelação, isto é, a aparição de Verbo enquanto prenhez simbólica exemplar, e por isso suprema, através de uma escrita, uma cultura. ${ }^{15}$

Mas, a despeito da atemporalidade que a caracteriza, a palavra das Escrituras, utilizada como epígrafe, como já salientou Jorge Schwartz, ao ser inserida em um novo contexto, sintetiza um dinâmico jogo de tempos: está conectada à ancestralidade do livro sagrado (passado) e o deslocamento do seu contexto a presentifica no novo texto, que,

adquire dimensão de futuridade na medida em que a epígrafe ocupa sempre um momento anterior a ele. Privilegiada por catalisar tempos narrativos em diversos níveis, aponta continuamente para o seu próprio passado, ao mesmo tempo que anuncia o texto que lhe segue, fazendo-se presente no ato de sua leitura. ${ }^{16}$

Em Murilo Rubião, todas as epígrafes são bíblicas com a significativa exceção de uma extraída das Memórias póstumas de Brás Cubas "Marcela amou-me durante quinze meses e onze contos de réis" - que, juntamente com uma de Jeremias, antecede o conto "Memórias do contabilista Pedro Inácio".

Sabemos o quanto a Bíblia representa para o escritor mineiro, pois ele tributa a esse livro santo a sua preferência pelo fantástico. Além disso, como o escritor declarou várias vezes, é de Machado que recebeu sua grande influência, e somente ele foi considerado digno de ocupar um lugar junto à

${ }^{15}$ DURAND, Gilbert. A fé do sapateiro. Brasília: Ed. Đda Universidade de Brasília, 1995.

p.45-6.

${ }^{16}$ SCHWARTZ, Jorge. Murilo Rubião: a poética do uroboro.São Paulo: Ática, 1981. p. 4. 
palavra das Escrituras.

Entretanto não estamos diante de um autor religioso, ainda que tenha sido muito católico numa determinada etapa de sua vida, chegou a ser místico, depois se tornou ateu para, finalmente, fixar-se no agnosticismo. Mas há nele uma nostalgia do divino que perpassa toda sua obra e que o fez declarar que desejaria morrer católico. Quando fala do abandono do catolicismo, ele diz:

O catolicismo está muito mais ligado à morte do que à vida, e transforma mesmo a vida em morte. Daí eu ter partido não para a eternidade que me ensinaram, mas para a eternidade já na própria vida. Desse modo a vida seria apenas uma coisa circular que não chegaria nunca àquela eternidade, mas também nós nunca poderíamos nos livrar dela. ${ }^{17}$

Eis aí o movimento recorrente, unitário e circular de que fala Arrigucci Júnior, confirmado pelo próprio ficcionista, sendo a Bíblia "uma espécie de fonte perene onde os argumentos estão sempre à mão, para serem colhidos e reescritos, reatualizados na recorrência perpétua do tempo" ${ }^{18}$. Ela é uma espécie de texto maior que as narrativas murilianas multiplicam.

Schwartz ${ }^{19}$, no interessante estudo que realiza sobre elas, examina-as, primeiramente na seqüência em que aparecem em $O$ ex-mágico, na sua relação umas com as outras, chegando a descobrir surpreendentes "pontos narrativos" 20 , que constituem uma história independente, concluindo que elas representam tematicamente "um espelho redutor dos contos" ${ }^{21}$. De forma surpreendente, o autor conclui que a leitura linear desses pequenos textos sintetiza os grandes temas da obra de Murilo Rubião. Num segundo momento, Schwartz as relaciona com as que ocorrem nos outros livros, não mais as analisando em sua linearidade, mas, a partir do que ele chama de uma "epígrafe matriz" 22 , as reúne, por similitude, em verdadeiros feixes epigráficos que denunciam seu caráter circular e repetitivo, que reiteram os movimentos recorrentes.

Segundo Arrigucci Júnior, o mesmo princípio estrutural que se observa no processo de escrita e no tratamento concedido aos temas, repete-se

${ }^{17}$ MURILO Rubião. Busca desesperada da clareza, p. 4.

${ }^{18}$ ARRIGUCCI JÚNIOR, op. cit., p. 151.

${ }^{19}$ SCHWARTZ, Jorge, op. cit., p.33.

${ }^{20}$ Ibid., p.5.

${ }^{21}$ Ibid., p.3.

${ }^{22}$ Ibid., p.3. 
CÁNOVAS, Suzana Yolanda L. M.

na utilização das epígrafes. O movimento constante e circular se multiplica indefinidamente repisando a rotina, que está ameaçada pela esterilidade. E é aí que o crítico detecta o procedimento irônico presente na utilização mesma do Verbo:

Nos limites - princípio e fim - a multiplicação é roída pela ameaça de esterilidade. A Bíblia se transforma num repaldo irônico para essa ameaça, porque acaba sendo reduzida, também ela, a mero meio de eficácia duvidosa, para salvar o escritor de falta de inspiração, do horror do princípio estéril $[. . .]^{23}$

Como tantos dos procedimentos do escritor, também esse aparece tematizado no interior da própria obra literária. Em "Marina, a intangível”, o jornalista, na solidão da madrugada, busca inspiração para vencer a esterilidade da página em branco, mergulhando na fonte perene representada pelo livro santo: "De novo abri a Bíblia. [...] O silêncio se desfizera e, mesmo sabendo que as horas eram marcadas por um relógio inexistente, tinha certeza de que o tempo retomara o seu ritmo." ${ }^{24}$ Aqui observamos, com Arrigucci Júnior, " uma abolição do valor sagrado do mito, degradado, pela ironia, à mera repetição ritualística do movimento recorrente da narração e do tempo ${ }^{25}$.

O crítico, valendo-se de pressupostos de Sartre, que afirma que o fantástico é a rebelião dos meios contra os fins ${ }^{26}$, declara que "o princípio fundamental da multiplicação dos meios subverte ironicamente a ordem do mundo, cria o mundo invertido do fantástico, onde não se tem acesso aos fins e os meios se converteram em fins em si mesmos"27. Daí o crítico afirmar que, para vencer a esterilidade da página em branco, é preciso valer-se do fantástico, como se narrar fosse uma recorrência ao insólito. Em decorrência disso, o mágico será considerado como o protótipo do artista, pois é ele o metamorfoseador por excelência. Resulta daí que o mágico, de tanto multiplicar os meios para fugir da rotina, acaba rotinizando a própria mágica, que, ironicamente, não se mostra diferente do fazer burocrático.

Por fim, identificamos o mesmo movimento recorrente no tratamento

${ }^{23}$ ARRIGUCCI JÚNIOR, op. cit., p. 152.

24"Marina, a intangível", p. 79.

${ }^{25}$ ARRIGUCCI JÚNIOR, op. cit., p. 153.

${ }^{26}$ SARTRE, Jean-Paul. Aminadab, ou o fantástico considerado como uma linguagem. In:

Situações I. Lisboa: Europa-América, 1968. p. 108-126.

${ }^{27}$ ARRIGUCCI JÚNIOR, op. cit., p. 153. 
concedido ao tempo, pois a narrativa de Murilo Rubião apresenta-se atemporal, com frágil linearidade narrativa. O tempo da narrativa constitui-se de idas e vindas, de coisas que se fazem e se desfazem numa tentativa inútil de corrigir a irreversibilidade histórica.

Em alguns relatos, há um vaivém no tempo. Em "Mariazinha" há um voltar atrás de vinte anos para, por assim dizer, corrigir os eventos históricos - a sedução de Mariazinha e as honras episcopais sonhadas por Dom Delfim - mas tudo resulta inócuo. Em "A flor de vidro", há um recuar de doze anos, e a narrativa não progride, reiterando-se, no texto, a imagem de Marialice, preenchendo vazios no ambiente, e o cumprimento de uma maldição -"Tomara que um galho lhe fure os olhos, diabo!" 28 . Em "A noiva da casa azul", o protagonista vai encontrar a namorada para pedi-la em casamento, mas a moça está morta há muitos anos e as casas de campo estão em ruínas.

Em "A casa do girassol vermelho", há nítida atemporalidade naquele dia de "alegria desbragada" 29 , que foi o primeiro e o último e em que se comemora a libertação do jugo de um pai castrador. As personagens só se dão conta do tempo histórico após o delírio que havia tomado conta delas: "As horas haviam passado despercebidas, como também se extinguira o delírio que, desde aquela tarde, nos tomara de assalto. A noite já começara a fragmentar o dia." ${ }^{30}$ Após o desaparecimento do rebelde companheiro, que morre afogado na represa, "iam-se os anos heróicos da luta contra o velho Simeão" 31 . "A casa do girassol vermelho se dobraria sobre as próprias ruínas." 32

Assim, verificamos um movimento recorrente, unitário e circular que detectamos no processo de escrita do autor, no tratamento concedido aos temas, nas epígrafes e no tratamento concedido ao tempo e que pode ser simbolizado pela imagem do uroboro, a serpente cósmica que morde a própria cauda. Segundo Chevalier e Gheerbrant, ela "simboliza um ciclo de evolução encerrado nela mesma [...] contém ao mesmo tempo as idéias de movimento em torno de si mesma, de continuidade, de autofecundação e, em conseqüência, de eterno retorno"33.

Observamos que "A casa do girassol vermelho" é o segundo conto da

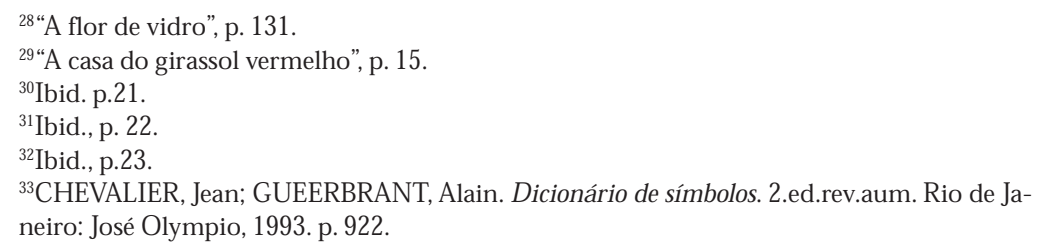


CÁNOVAS, Suzana Yolanda L. M.

coletânea Contos reunidos, ordem que é estabelecida pelo escritor, quando do lançamento de $O$ ex-mágico, e mantida na publicação póstuma. Não nos parece isento de significação que, na abertura de uma obra literária, seja apresentado o mágico, o protótipo do artista e, imediatamente, um espaço em ruínas. Desde logo já vem representada a imagem que vai constituir-se no espaço degradado de Murilo Rubião. Há o aspecto fragmentário e fantasmagórico de um mundo como de uma cidade em ruínas, precocemente envelhecida e gasta. Na verdade, esse é o espaço prototípico de Murilo Rubião, que aparecerá em suas nuanças de destruição, enclausuramento, invasão e degradação.

Ao que tudo indica, a sensação de enclausuramento tem origem na própria situação geográfica de Minas. Tal aspecto aparece em "Ofélia, meu cachimbo e o mar" em que o protagonista que é "de um vilarejo de Minas, agoniado nas fraldas da Mantiqueira" ${ }^{34}$, devaneia à noite com o mar, narrando episódios de sua família de marujos à cachorra Ofélia. Dessa forma, o mar constitui-se num local de sonho e de evasão.

Quanto ao campo, ainda que proporcione idílicas paisagens, aparece sempre contaminado pela dor e pela violência. Em "A casa do girassol vermelho", a paisagem, "com seus imensos jardins, longe da cidade e do mundo" ${ }^{35}$, que poderia fornecer todos os elementos para uma vida feliz, há o que Antônio Manuel dos Santos Silva denomina de "infernalização do aprazível" 36 , pois os eventos transcorrem numa " manhã quente, queimada por um sol violento" ${ }^{37} \mathrm{em}$ que as personagens, tomadas por uma "centelha diabólica" 38 , sentem uma "alegria física, desbragada" ${ }^{39}$. Nesse paraíso conspurcado que irrevogavelmente se encaminha para as ruínas, há represálias, violência e morte. Em "A flor de vidro", repete-se o espaço campestre e até mesmo o nome de uma personagem, Marialice, mas o paraíso carece da presença da mulher amada, e há o cumprimento de uma maldição. Em "Bruma", o campo é cenário da disputa de irmãos inimigos Og e Godofredo, ainda que o rancor provenha apenas de uma das partes. Também aqui a evocação da imagem da mulher ausente preenche os espaços vazios. Na verdade, parece não haver paz para as personagens de Murilo Rubião, tal é

34"Ofélia, meu cachimbo e o mar", p. 114.

35 "A casa do girassol vermelho", p. 16.

${ }^{36}$ SILVA, Antônio Manuel dos Santos. Os espaços da solidão. In: SOUZA, Eneida Maria de ; PINTO, Júlio César Machado. (Orgs.). In: SIMPÓSIO DE LITERATURA COMPARADA, 1. e 2., 1987, Belo Horizonte. Anais...Belo Horizonte: Imprensa da Universidade Federal de Minas Gerais, 1987. v. 2.

37" A casa do girassol vermelho", p. 16.

38 "A casa do girassol vermelho", p. 17.

${ }^{39}$ Ibid., p. 15. 
o que nos faz concluir Alfredo, do conto homônimo, que precisa se metamorfosear e transpor simbólicos níveis cósmicos para fugir do convívio humano: "Atravessaria outras cordilheiras, azuis como todas elas. Alcançaria vales e planícies, ouvindo rolar as pedras, sentindo o frio das manhãs sem sol. E agora sem a esperança de um paradeiro." ${ }^{40}$.

Está o campo em oposição à cidade, que pode assumir amplas proporções, alargando-se para incluir o mar e se apresentando como local de uma busca inútil ("Epidólia"), ou reduzir-se a uma aldeia ("A diáspora”, invadida por forasteiros que poluem seu espaço a ponto de torná-lo um inferno. A cidade é também o local de condenação de Cariba ("A cidade"), de Cris ("A lua") e de Botão-de-Rosa ("Botão-de-Rosa") ou de eventos inusitados como uma invasão de dragões ("Os dragões"), ou de um homem que vai emagrecendo até cuspir fogo e desaparecer ("O homem do boné cinzento").

A casa assume também as mais inusitadas feições, porém ela não é quase nunca um lar, mas um espaço ameaçador. Assim a transformam as ninhadas de filhos de Aglaia ("Aglaia”), ou o terrível quadro da mãe de Éolo ("Petúnia”). Conto exemplar nesse sentido é "O lodo" em que o protagonista tem sua casa invadida pela irmã e o filho mentecapto. Aqui a personagem tem não somente o seu espaço de privacidade invadido, mas também o reduto do próprio corpo, de onde brotam chagas de pétalas escarlates, que estão associadas à culpa do incesto.

Da casa se evadem para as ruas, hotéis, restaurantes ou tabernas, os solitários e os banidos. Há momentos em que a casa, por não se constituir num local de preservação da identidade que, aliás, não se fixa, não aparece devidamente determinada, como é o caso de "Os três nomes de Godofredo", cujo protagonista não consegue identificar onde vive, como não reconhece a(s) esposa(s) e até mesmo seu próprio nome. A construção humana, cuja função básica deveria ser servir de abrigo, assume proporções desmesuradas e sem finalidade conhecida ("O edifício") ou é, paulatinamente, desconstruída, encurralando o protagonista que já abandonara um lar problemático ("O bloqueio"). Também os restaurantes, que deveriam propiciar momentos agradáveis do desfrutar de iguarias e convívio humano, tornam-se locais de aprisionamento e perplexidade ("Os comensais" e "Os três nomes de Godofredo").

Em resumo, quanto aos aspectos estruturais que constituem uma narrativa, o mundo muriliano apresenta um narrador que é o oposto do demiurgo; personagens solitárias e enclausuradas que penetram numa ab-

\footnotetext{
40"Alfredo”, p. 69. Grifo nosso.
} 
CÁNOVAS, Suzana Yolanda L. M.

surda e inexplicável situação existencial para a qual não há saída; há uma destruição da sucessão causal do tempo e do enredo, e os espaços estão reduzidos a ruínas. Nesse universo degradado, resta o compensador mundo dos sonhos ou do devaneio, no qual assumem relevância a profusão de cores do arco-íris ou a vastidão do oceano.

\section{BIBLIOGRAFIA}

ARRIGUCCI JÚNIOR, Davi. Minas, assombros e anedotas (Os contos fantásticos de Murilo Rubião). In: Enigma e comentário: ensaios sobre literatura e experiência. São Paulo: Companhia das Letras, 1987.

CHEVALIER, Jean; GUEERBRANT, Alain. Dicionário de símbolos. 2.ed. rev. aum. Rio de Janeiro: José Olympio, 1989.

COUTINHO, Edilberto. No habló, não estava com nada. O Globo, Rio de Janeiro, 07 abr. 1977.

DURAND, Gilbert. A fé do sapateiro. Brasília: da Universidade de Brasília, 1995.

FREUD, Sigmund. O estranho. In:__. Edição standard das obras psicológicas completas de Sigmund Freud. Rio de Janeiro: Imago, 1986. v. 17. p. 271-314.

MOURÃO,Rui. Um discípulo de Machado. Suplemento Literário do Minas Gerais. Belo Horizonte, v. 22, n. 1.062, 21 fev. 1987. (Especial 3). Publicado anteriormente no Suplemento Literário do Minas Gerais, Belo Horizonte, 14 jul. 1974.

MURILO Rubião. Busca desesperada da clareza. In: __. Seleção de textos, notas, estudos biográfico, histórico e crítico e exercícios por Jorge Schwartz. São Paulo: Abril Educação, 1982. (Literatura comentada).

PELLEGRINO, Espelho dos escritores.Suplemento Literário do Minas Gerais, Belo Horizonte, v. 22, n. 1.061, 14 fev. 1987. (Especial 2 ). Texto publicado primeiramente na Revista da Semana, edição de 23 de janeiro de 1954.

RUBIÃO, Murilo. Contos reunidos. São Paulo: Ática, 1998.

. Auto-retrato. In: NUNES, Sandra Regina Chaves. Murilo Rubião: escrita e reescrita. 1996. Dissertação (Mestrado em Comunicação e Semiótica) - Pontifícia Universidade Católica, São Paulo, 1996.

SARTRE, Jean-Paul. Aminadab, ou do fantástico considerado como uma linguagem. In Situações I. Lisboa: Europa-América, 1968. p. 108-126. 
SCHWARTZ, Jorge. Murilo Rubião: a poética do uroboro. São Paulo: Ática, 1981.

SILVA, Antônio Manuel dos Santos. Os espaços da solidão. In: SOUZA, Eneida Maria de; PINTO, Julio César Machado. (Orgs.). SIMPÓSIO DE LITERATURA COMPARADA, 1 e 2, 1987, Belo Horizonte. Anais... Belo Horizonte: Imprensa da Universidade Federal de Minas Gerais, 1987. v.2. 